\title{
Laboratory Investigation on Skid Resistance of Hot Mix Asphalt Pavement with Nano Crumb Rubber Contribution
}

\author{
Sigit P.Hadiwardoyo*, Oliver Senawibowo, R. Jachrizal Sumabrata, Dadang Iskandar \\ Civil Engineering Department, Faculty of Engineering, Universitas Indonesia, Depok, 16424, Indonesia
}

Received February 25, 2020 ; Revised June 24, 2020; Accepted July 7, 2020

Copyright $@ 2020$ by authors, all rights reserved. Authors agree that this article remains permanently open access under the terms of the Creative Commons Attribution License 4.0 International License

\begin{abstract}
As the number of vehicles increases, the increasing number of used tires becomes an important issue, which needs to be handled so as not to become waste. One method that has been widely used is to process used tires into Crumb Rubber which in the field of road pavement can be utilized as added material. Hot mix asphalt concrete has a service life based on the mixture's mechanical strength, but its slip resistance is another important thing. The slip resistance is influenced by the composition of asphalt concrete aggregate as well as temperature. The increase of asphalt concrete mixture, whose content will experience an increase in temperature, will decrease the value of its slip resistance because asphalt becomes softer, which will result in a decrease in the bonding ability between asphalt and aggregate. Crumb Rubber is refined into Nano-sized particles in hot mix asphalt concrete. The percentages of Nano Crumb Rubber used in asphalt content are 0\%, 2.5\%, and $5 \%$ by using the dry process method. This skid resistance test is performed by using a British Pendulum Tester and carried out under various temperature conditions, $26{ }^{\circ} \mathrm{C}, 30{ }^{\circ} \mathrm{C}, 35{ }^{\circ} \mathrm{C}, 40{ }^{\circ} \mathrm{C}$, and $45{ }^{\circ} \mathrm{C}$. Test results have shown that at normal temperature $\left(25^{\circ} \mathrm{C}\right)$ asphalt modification is smaller than the asphalt mixture of virgin asphalt. However, at temperatures above $40{ }^{\circ} \mathrm{C}$ the opposite occurs, especially in the addition of $2.5 \%$. The addition of Nano Crumb Rubber $2.5 \%$ has reduced the effect of high temperature more than $40{ }^{\circ} \mathrm{C}$ on the asphalt mixture.
\end{abstract}

Keywords Crumb Rubber, Skid Resistance, Temperature, Hot Mix Asphalt

\section{Introduction}

Skid resistance (SR) is the force that results from friction between the vehicle's tire and the road surface layer. This resistance force is produced through wheel rotation or sliding on the pavement surface (Hall, K.L. Smith, \& L. Titus-Glover, 2009). SR has a value of friction caused by friction between the pavement surface and vehicle tires. In general, the value of SR on the dry road surface is relatively high compared to the wet road surface, so the measure used in planning is based on the condition of the wet road. This value is an essential part of road pavement for vehicle safety aspects. Pavement surfaces in wet conditions that have inadequate SR can endanger moving vehicles, especially for motorbikes. This type of mode of transportation is widely used in Indonesia in big cities and small cities.

In terms of pavement engineering, there are two groups of technical parameters that affect changes of SR. The first is the inherent property of pavement, such as aggregate and asphalt mixture properties, and second are external factors, such as weather, traffic polishing, and contaminants (Zheng, Qian, Liu, \& Liu, 2018). Vehicles with low speed will have enough time to process the discharge of water between the road surface and vehicle tires. However, with increasing speed, the time for the process of flowing water will be reduced. Evaluation of texture properties on asphalt pavement surfaces is generally carried out by sand patch test, British Pendulum test, and drainage test. These tests are usually carried out in the field after road pavement construction (Araujo, Bessa, \& Castelo Branco, 2015).

One method used to measure the value of SR on the road surface is the British Pendulum Tester (BPT). This BPT is a test tool by using the dynamic pendulum, which is used to measure the energy lost when the rubber part is under the base of the pendulum rubs on a flat surface and measures the polishing value of the curved test specimen. The unit of roughness value is expressed in the British Pendulum Number (BPN); this value represents the characteristics of 
skid or friction. The interaction between the surface of the road and the surface of the vehicle tire. This is called micro-texture, while the macrotexture is the irregularity of the road surface. This condition is formed by the regulation of aggregate particles and their interactions with asphalt binders and air cavities (Praticò\&Astolfi, 2017). SR of the pavement surface can be improved by using a macro texture design. Related macro texture standards have been developed to evaluate asphalt pavement skid resistance in many countries and influenced by aggregate particle size, shape, and distance between aggregates (Hu et al., 2016). SR will approach to stabilty when the thickness of the water film is less than the micro-texture. As the water layer increases, Skid resistance will drop sharply until the macrotexture reaches its capacity, and SR does not change again (Chou, Lee, Chen, \& Wu, 2017).

Due to the difficulty of controlling vehicles and slippery road surfaces, successive collisions in wet road conditions caused by water on the road surface during rain often occur. Road accidents during wet weather have become the primary concern of road engineers in wet climates. To minimize the occurrence of wet weather road accidents, road agents responsible for maintaining a road pavement network monitor on SR pavements actively take preventive or corrective action if necessary to keep the road surface safe for driving in wet weather (Fwa, 2017). Changes in the value of SR from the road surface decrease due to vehicle wheel trajectories on the road surface. The wheels of the vehicle grind the road surface continuously until the surface becomes slippery. Low SR means harmful friction and can increase the risk of an accident. Decreasing vehicle speed to achieve safety requires high anti-skid performance at the micro-texture and macrotexture levels. British Pendulum Number is a measuring tool to determine the energy loss of a rubber slider driven on the road surface. This tool is to determine the microstructure characterization of low-speed friction (Lin \&Tongjing, 2018).

Asphalt road surface consists of aggregate bound by asphalt, bonding between aggregates can affect SR, and therefore the characteristics of asphalt become an essential part of getting a good SR. The value of SR is also influenced by the binding material between the layers of the road surface. The friction between the two layers of road pavement is formed from the attachment of aggregate particles needed to obtain high friction performance between the two surfaces (Lastra-González, Indacoechea-Vega, Calzada-Pérez, Castro-Fresno, \& Carpio-García, 2017). The coating with asphalt mixture on the concrete pavement surface is influenced by the performance of the binder. The surface of a concrete road or an asphalt road requires the same level of surface roughness, so engineers must focus on the surface of the asphalt road. The roughness of the concrete road surface will be reduced due to the friction of vehicle tires with a concrete road surface, which can be improved by adding a layer of asphalt pavement on the concrete road surface layer (Hadiwardoyo, Sinaga, \&Fikri, 2013).

Asphalt as a binding agent between aggregates can be improved by mixing additive material in the asphalt concrete mixture. Various types of additive materials have been widely used and researched various achievements. Some researchers have done a lot of researches with the use of waste materials to improve the performance of asphalt concrete mixtures. One of the materials used is vehicle tire waste. The waste tire is processed into materials such as fibrous powder. Asphalt with rubber mixture is considered to have a better pavement quality than without. The rubber content can increase crack resistance and groove deformation. The Ministry of Public Works and Housing has issued regulations No.04/SE/M/2019 regarding norms, standards, procedures, and manuals for the use of rubber for asphalt mixtures.

In general, the application of crumb rubber (CR) as an asphalt binder added material is intended to improve the nature of the binder by reducing the temperature susceptibility of the binder (Jeong, Lee, Amirkhanian, \& Kim, 2010). Two methods are generally followed to insert CR particles into the bitumen mixture, which are usually referred to as 'wet processes' and 'dry processes.' Traditionally, the dry process consists of adding CR at room temperature added to the heated aggregate mixture before adding the bitumen into the mixing process (Celauro, Celauro, Lo Presti, \& Bevilacqua, 2012; Feiteira Dias, Picado-Santos, \& Capitão, 2014; Moreno, Rubio, \& Martinez-Echevarria, 2012). Utilization of added material is not only carried out on hot asphalt mixes but also on warm asphalt mixes, and it is expected to obtain asphalt mixes with high performance and be friendly to the environment. The importance of using waste tire is regarded as a form of environmental concern and the development of CR utilization technology in several countries and studying the advantages of using CR as an asphalt modification material (Fontes, Trichês, Pais, \& Pereira, 2009; Martinho, Picado-santos, \&Capitão, 2017; Taylor \& Airey, 2007).

Warm asphalt mixture with zeolite as additives obtains higher Skid Number (SN) values than those without. This may be because natural zeolite additives contain water, which provides better lubrication when bitumen coats the aggregates in the mixing process (Anagi, Hadiwardoyo, Sumabrata, \&Wahjuningsih, 2017). Contact between the road surface and vehicle wheels is affected not only by road characteristics but also by vehicle tire characteristics. Grooves on the tire surface will continue to decrease due to friction with the road surface. Tire characteristics that affect SR include tire surface thread design, rubber composition, tire pressure, inflation, temperature, and load distributed through the vehicle axis (Bianchini, Heitzman, \&Maghsoodloo, 2011).

In some tropical countries, road surface conditions are an essential concern because the increase in road surface 
temperature affects the performance of concrete asphalt roads. Especially in the rainy season, the presence of water on the surface of the road can cause accidents of a vehicle slipping. One of the most important ways to evaluate the level of road surface safety is SR. The influence of temperature changes on the SR has been done by several researchers. BPN values decrease by 0.35 for every $1{ }^{\circ} \mathrm{C}$ rise in temperature (El-Desouky, 2018). Previous studies have used CR fibre as an added material. The constraints of using this material in the wet mixing process are the difficulties of forming a mixture that spread between asphalt and CR. In this study, CR has been refined to Nano-size. The mixing process becomes more accessible than CR fibre, and the function of added material can fill the aggregate cavities and fill the space between aggregates.

\section{Materials and Methods}

\section{Nano crumb rubber}

CR material is processed from used tires through an ambient grinding process at PT Daurindo Indonesia, Bogor Indonesia. The ambient process is done automatically, which is processed at room temperature. Used tire material is crushed into fibre particles, and the ambient process uses a series of machines consisting of 3 stages. In the first stage, used tires are inserted into the granulation machine or cracker mills and are turned into small particles. Then in the second stage, the particle enters another machine that will grind to separate the particle from metal and fabric. Each process includes a filter to separate large sizes and small, large particles and mill. The third stage is the separation of metal and cloth which are removed by magnetism with an air separator. The next process is carried out in the laboratory to find out more about the use of CR further milling until it reaches Nano size (Figure1), which then is called Nano Crumb Rubber (NCR).

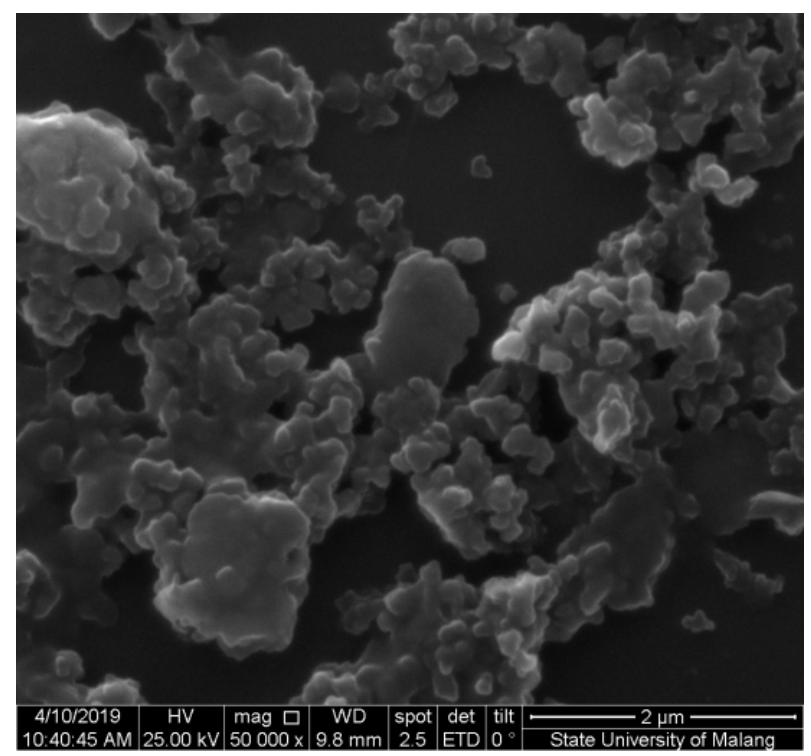

Figure 1. SEM image Nano Crumb Rubber

\section{Asphalt}

The first material test is the characteristics of asphalt to check the suitability of asphalt with 60/70 pen asphalt specifications. Asphalt testing consists of; bitumen material Penetration, Penetration TFOT, asphalt softening point, flash point, ductility, and density, as in Table 1.

Based on testing, the characteristics of virgin asphalt and asphalt modifications have been carried out and shown in Table-1. The penetration value of asphalt at $25^{\circ} \mathrm{C}$ has increased with the addition of (NCR). The data in this table show changes in other asphalt characteristics such as asphalt softening points, and there is a significant decrease in the asphalt modification for the ductility value.

Table 1. Asphalt Test Results

\begin{tabular}{lccccc}
\hline \multicolumn{7}{c}{ Asphalt Characteristics } & & & \\
\hline \multicolumn{1}{c}{ Type of testing } & Virgin & NCR & NCR & NCR & NCR \\
& Asphalt & $\mathbf{1 . 2 5 \%}$ & $\mathbf{2 . 5 \%}$ & $\mathbf{3 . 7 5 \%}$ & $\mathbf{5 . 0 \%}$ \\
\hline Penetration of materials $\left(25^{\circ} \mathrm{C}\right)$ & 62.5 & 64 & 67 & 65 & 66 \\
Oil and asphalt weight loss (TFOT) & 0.108 & 0.109 & 0.11 & 0.106 & 0.104 \\
Penetration TFOT & 61 & 58 & 54.7 & 56 & 55 \\
Asphalt softening point $\left({ }^{\circ} \mathrm{C}\right)$ & 45 & 47 & 48 & 47 & 46 \\
Flash point $\left({ }^{\circ} \mathrm{C}\right)$ & 306 & 295 & 274 & 280 & 298 \\
Solubility $(\%)$ & 99 & 99 & 99 & 99 & 99 \\
Ductility (mm) & 1,070 & 440 & 330 & 390 & 372 \\
Spesific gravity & 1.048 & 1.049 & 1.05 & 1.051 & 1.052 \\
\hline
\end{tabular}




\section{Aggregate}

Aggregates in this study were obtained from PT. KADI, consisting of three types of sizes; coarse aggregate, medium aggregate, and fine aggregate. In this research, the middle specification aggregates from those set for hot mix asphalt have been used (Table 2). Asphalt mixture in this study has been used wearing course from Indonesian specifications. A series of aggregate tests have been carried out to determine specific gravity and abrasion with a Los Angeles machine.

Table 2. Aggregate Gradation

\begin{tabular}{cccc}
\hline Sieve No & $\begin{array}{c}\text { AC-WC } \\
\text { Specification }\end{array}$ & $\begin{array}{c}\text { Middle } \\
\text { Specification }\end{array}$ & \% Weight \\
\hline $3 / 4 ”$ & 100 & 100 & 0 \\
$1 / 2 ”$ & $90-100$ & 95 & 5 \\
$3 / 8 ”$ & $77-90$ & 83.5 & 11.5 \\
4 & $53-69$ & 61 & 22.5 \\
8 & $33-53$ & 43 & 18 \\
16 & $21-40$ & 30.5 & 12.5 \\
30 & $14-30$ & 22 & 8.5 \\
50 & $9-22$ & 15.5 & 6.5 \\
100 & $6-15$ & 10.5 & 5 \\
200 & $4-9$ & 6.5 & 4 \\
pan & 0 & 0 & 6.5 \\
\hline
\end{tabular}

\section{Marshall Test}

Marshall testing in this study was conducted to determine the stability of asphalt mixtures in conditions of the specimen Marshall Standard. Marshall standard test is performed on samples containing asphalt with a percentage of $5 \%, 5.5 \%, 6 \%, 6.5 \%$, and $7 \%$ of the sample weight. From this Marshall test, the optimum asphalt content obtained on optimum asphalt content of $6 \%$, and this value is used in the Marshall test on modified asphalt mixture.Marshall test on modified asphalt mixture uss specimens consisting of a mixture of virgin asphalt, and aggregate by adding NCR.The Marshal Test results have been used as a reference to density values for BPN samples with NCR 2.5\% and 5\%.

\section{Skid Resistance}

One method used to measure the SR value of a road surface is the BPT. The BPT tool is a dynamic pendulum-type test used to measure the energy lost when the rubber at the bottom of the pendulum touches a flat surface and measures the polishing of the test object by measuring the skid value recorded as the BPN. This value represents the properties of obstacles, surface or friction.

This test uses a modified BPT tool; this tool is usually used on the road surface to measure SR but in this study used in the laboratory. The BPT tool in this study has been modified by adding a water reservoir placed at the base of the sample placement (Figure 2). The water tank is used to condition the temperature of the sample by heating the water to the desired temperature. The water level in the reservoir is fixed until the sample surface reaches wet. How to measure temperature is done on the surface of the sample. The sample's position to measure the surface temperature of the sample has illustrated the measurement of temperature on the road surface. The sample is compacted by using a wheel-tracking machine compactor with the density level adjusted to the density from the Marshall test. The sample is cut according to the needs of the BPN test sample size (Figure 3).

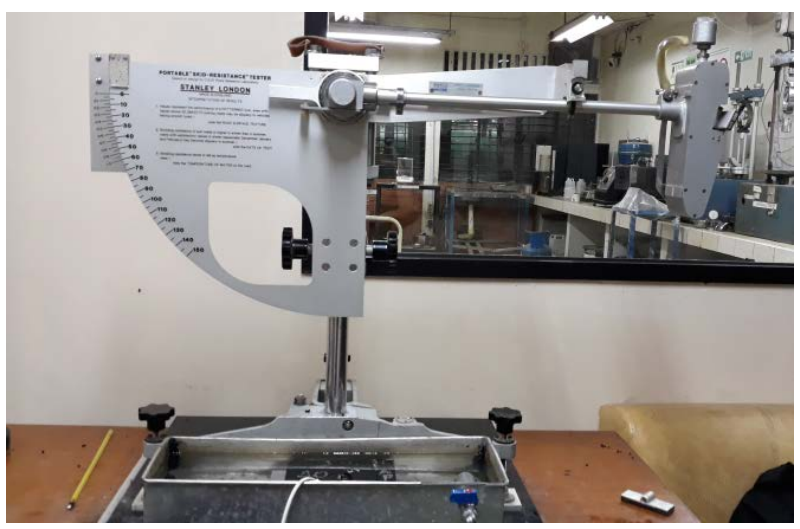

Figure 2. Modified British Pendulum Tester

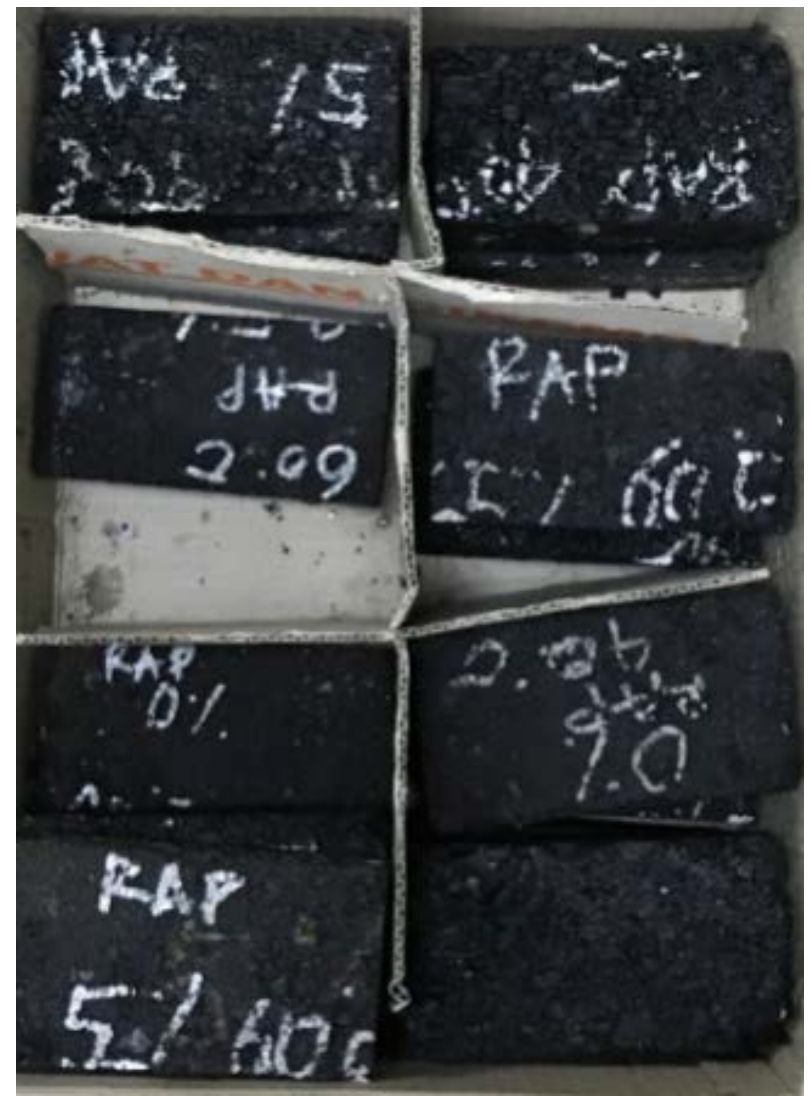

Figure 3. Skid Resistance Sample 
This test is carried out at five different temperatures, 26 ${ }^{\circ} \mathrm{C}, 30{ }^{\circ} \mathrm{C}, 35{ }^{\circ} \mathrm{C}, 40{ }^{\circ} \mathrm{C}$, and $45{ }^{\circ} \mathrm{C}$ to illustrate the conditions in the field that have varying temperatures and also to determine the characteristics of asphalt during the increase or decrease in temperature. Before the testing is done, we should adjust the tool's position in a flat position by adjusting its height. The rubber at the base of the pendulum is sure to touch the surface of the test specimen along $124-127 \mathrm{~mm}$ by adjusting the length of the pendulum rod. BPN temperature correction is $0-3$ for measurements between $27{ }^{\circ} \mathrm{C}-37{ }^{\circ} \mathrm{C}$. This value is the correction of the BPN test results due to temperature differences. Skid Number values are calculated by using the equation:

$$
\mathrm{SN}=0.862(\mathrm{BPN})-9.69
$$

\section{Results and Discussion}

\section{British Pendulum Number (BPN)}

The test is carried out after all the equipment is ready for use, such as adjusting the length of the contact area, calibration of the inclination of the BPT tool using a water pass, and setting the scale reading needle. The test is carried out by placing the specimen submerged in water in a tub. The BPN pendulum is swung five times for each temperature change. There are two ways of testing samples, and in a first way, the sample is tested at each additional temperature from $26^{\circ} \mathrm{C}$ to $45^{\circ} \mathrm{C}$, in the second way the sample is replaced every five times the temperature change. Data obtained from each temperature of 10 test results can be seen in Figure-4.

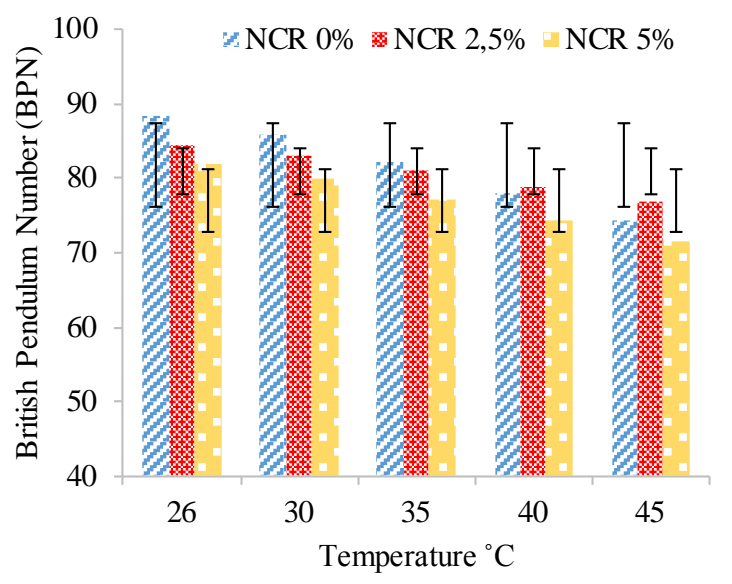

Figure 4. BPN value and temperature

Figure-4 shows that the BPN value of virgin asphalt decreases faster than the modified asphalt mixture using Nano Crumb Rubber. The value of BPN continues to decrease due to increasing temperature; this is because the asphalt mixture becomes softer than before. The addition of $2.5 \%$ NCR looks better than the addition of 5\% NCR. At temperatures of $25^{\circ} \mathrm{C}$ to $35^{\circ} \mathrm{C}$, the virgin asphalt mixture produces a higher BPN value than the modified asphalt mixture.

The addition of $2.5 \%$ NCR at temperatures above $40^{\circ} \mathrm{C}$ produces a higher BPN value than the asphalt virgin mixture. This change follows the softening point value of virgin asphalt and modified asphalt. The modified asphalt with an additional NCR of $2.5 \%$ has a softening point value of $48{ }^{\circ} \mathrm{C}$ higher than the others. The results of this test indicate that the softening point value of asphalt mixture also affects the amount of BPN.

\section{Skid Number (SN)}

After obtaining the temperature correction, BPN value proceeds with calculating the value of the skid number as written in equation (1). Skid Number is a unit used to measure SR that occurs on a road surface, higher than the skid number value.

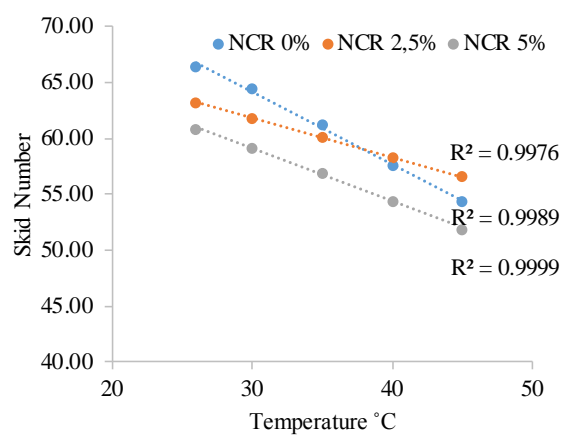

Figure 5. SN value and temperature

Figure 4 shows the trend line with r2 value is close to 1 ; all of them form a linear equation that connects the Skid Number value with temperature. From Figure 5, it can be seen that there is a more significant decrease in $\mathrm{SN}$ value in the virgin asphalt mixture due to increasing temperature on the sample surface.

From the test results data can be made an equation to get the relationship between several variables that affect the value of $\mathrm{SN}$ as follows:

$$
\mathrm{SN}=\{(0.061 . \alpha-4.47) \mathrm{T}\}+\beta
$$

Where $\alpha$ is asphalt penetration at $25^{\circ} \mathrm{C}, \mathrm{T}$ is the temperature in ${ }^{\circ} \mathrm{C}$ on the sample surface, and $\beta$ is a constant. The $\beta$ value for virgin asphalt is 84 , while for modified asphalt is 73 .

Figure 6 shows the closeness between the calculations by using equation (2) and laboratory test results. $\beta$ value, there is a difference between a hot asphalt mixture and asphalt modification by using asphalt virgin and NCR.

This study uses the same aggregate composition for each sample, so the difference in SN values is only influenced by the characteristics of asphalt. In this study, a significant difference from the characteristics of asphalt is the ductility value of asphalt. The addition of NCR has reduced the ductility value of asphalt modification. 


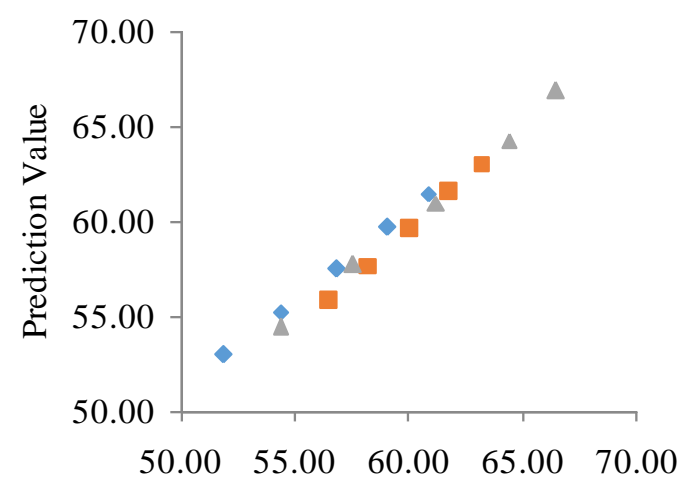

Test Result

Figure 6. Prediction Value and Test Results

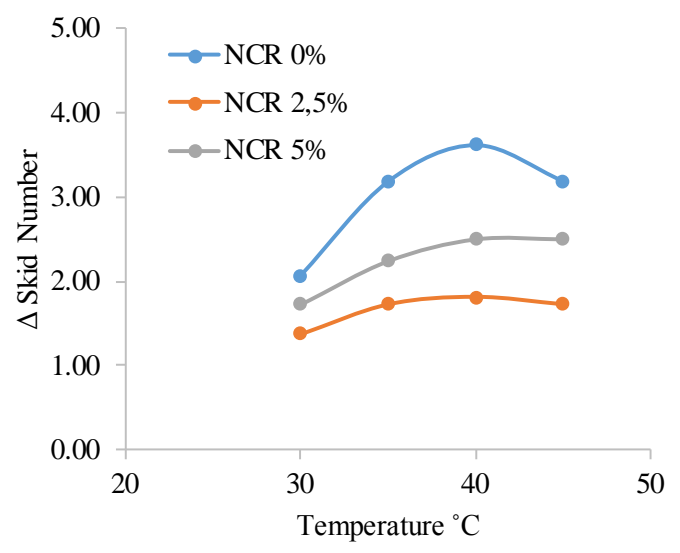

Figure 7. SN Value Difference and temperature

Figure-7 shows the rate of change in $\mathrm{SN}$ with changes in temperature. It can be seen that the rate of change in virgin asphalt is higher compared to modified asphalt. It can be used to strengthen the conclusion that the addition of NCR can slow down $\mathrm{SN}$ values. In other words that the addition of NCR can reduce the susceptibility of hot mix asphalt to SN values. The addition of NCR, $2.5 \%$ is better than $5 \%$. It is proved to be more resistant to temperature changes, even though the temperature of $26{ }^{\circ} \mathrm{C}$ has a lower SN value compared to virgin asphalt mixture.

\section{Conclusion}

A modified asphalt concrete mixture by using NCR added dry method was evaluated in the study. Based on the test results, it can be concluded as follows:

1. BPN value in the mixture by using virgin asphalt decreases more due to an increase in surface temperature compared to the modified asphalt mixture. This value is due to the lower softening point of virgin asphalt compared to modified asphalt.

2. Skid Number value at normal temperature $\left(25^{\circ} \mathrm{C}\right)$ asphalt modification is less than the mixture of virgin asphalt but at temperatures above $40^{\circ} \mathrm{C}$ the opposite occurs, especially in the addition of $2.5 \%$ NCR.

3. The addition of NCR to concrete asphalt mixture does not show the Skid Number value has resistance to the influence of temperature.

\section{Acknowledgments}

This research was funded by the DRPM Universitas Indonesia through the PIT-9 Grant 2019, funded by contract no. NKB-0076/UN2.R3.1/HKP.05.00/2019. The authors thank the Pusjatan Bandung, and the Structure and Material Laboratory of the Universitas Indonesia Civil Engineering Department.

\section{REFERENCES}

[1] Anagi, N., Hadiwardoyo, S. P., Sumabrata, R. J., \& Wahjuningsih, N. (2017). Performance of skid resistance of warm-mix asphalt with Buton natural asphalt-rubber (BNA-R) and zeolite additives as a result of road surface temperature changes. AIP Conference Proceedings, 1855. https://doi.org/10.1063/1.4985478

[2] Araujo, V. M. C., Bessa, I. S., \& Castelo Branco, V. T. F. (2015). Measuring skid resistance of hot mix asphalt using the aggregate image measurement system (AIMS). Construction and Building Materials, 98, 476-481. https://doi.org/10.1016/j.conbuildmat.2015.08.117

[3] Bianchini, A., Heitzman, M., \& Maghsoodloo, S. (2011). Evaluation of Temperature Influence on Friction Measurements. Journal of Transportation Engineering, 137(9), 640-647. https://doi.org/10.1061/(ASCE)TE.19435436.0000271

[4] Celauro, B., Celauro, C., Lo Presti, D., \& Bevilacqua, A. (2012). Definition of a laboratory optimization protocol for road bitumen improved with recycled tire rubber. Construction and Building Materials, 37, 562-572. https://doi.org/10.1016/j.conbuildmat.2012.07.034

[5] Chou, C. P., Lee, C. C., Chen, A. C., \& Wu, C. Y. (2017). Using a constructive pavement texture index for skid resistance screening. International Journal of Pavement Research and Technology, 10(4), 360-368. https://doi.org/10.1016/j.ijprt.2017.05.002

[6] El-Desouky, A. (2018). Investigating the effect of temperature variations on the measured airfield pavement skid resistance. Construction and Building Materials, 161, 649-653. https://doi.org/10.1016/j.conbuildmat.2017.11.150

[7] Feiteira Dias, J. L., Picado-Santos, L. G., \& Capitão, S. D. (2014). Mechanical performance of dry process fine crumb rubber asphalt mixtures placed on the Portuguese road network. Construction and Building Materials, 73, 247-254. https://doi.org/10.1016/j.conbuildmat.2014.09.110

[8] Fontes, L. P. T. L., Trichês, G., Pais, J. C., \& Pereira, P. A. A. (2009). Evaluating permanent deformation in asphalt rubber mixtures. Construsction and Building Materials, 370(6486), 
$170-171$.

https://doi.org/10.1016/j.conbuildmat.2009.12.021

[9] Fwa, T. F. (2017). Skid resistance determination for pavement management and wet-weather road safety. International Journal of Transportation Science and Technology, 6(3), 217-227. https://doi.org/10.1016/j.ijtst.20 17.08.001

[10] Hadiwardoyo, S. P., Sinaga, E. S., \& Fikri, H. (2013). The influence of Buton asphalt additive on skid resistance based on penetration index and temperature. Construction and Building Materials, 42, 5-10. https://doi.org/10.1016/j.conb uildmat.2012.12.018

[11] Hall, J. W., K.L. Smith, \& L. Titus-Glover. (2009). Guide for Pavement Friction. Guide for Pavement Friction, (February). https://doi.org/10.17226/23038

[12] Hu, L., Yun, D., Liu, Z., Du, S., Zhang, Z., \& Bao, Y. (2016). Effect of three-dimensional macrotexture characteristics on dynamic frictional coefficient of asphalt pavement surface. Construction and Building Materials, 126, 720-729. https://doi.org/10.1016/j.conbuildmat.2016.09.088

[13] Jeong, K. D., Lee, S. J., Amirkhanian, S. N., \& Kim, K. W. (2010). Interaction effects of crumb rubber modified asphalt binders. Construction and Building Materials, 24(5), 824831. https://doi.org/10.1016/j.conbuildmat.2009.10.024

[14] Lastra-González, P., Indacoechea-Vega, I., Calzada-Pérez, M. A., Castro-Fresno, D., \& Carpio-García, J. (2017). Analysis of the skid resistance and adherence between layers of asphalt concretes modified by dry way with polymeric waste. Construction and Building Materials, 133, 163-170. https://doi.org/10.1016/j.conbuildmat.2016.12.063
[15] Lin, C., \& Tongjing, W. (2018). Effect of fine aggregate angularity on skid-resistance of asphalt pavement using accelerated pavement testing. Construction and Building Materials, 168, 41-46.https://doi.org/10.1016/j.conbuildma t.2018.01.171

[16] Martinho, F. C. G., Picado-santos, L. G., \& Capitão, S. D. (2017). Mechanical properties of warm-mix asphalt concrete containing different additives and recycled asphalt as constituents applied in real production conditions. Construction and Building Materials, 131, 78-89. https://doi.org/10.1016/j.conbuildmat.2016.11.051

[17] Moreno, F., Rubio, M. C., \& Martinez-Echevarria, M. J. (2012). The mechanical performance of dry-process crumb rubber modified hot bituminous mixes: The influence of digestion time and crumb rubber percentage. Construction and Building Materials, 26(1), 466-474. https://doi.org/10.1016/j.conbuildmat.2011.06.046

[18] Praticò, F. G., \& Astolfi, A. (2017). A new and simplified approach to assess the pavement surface micro- and macrotexture. Construction and Building Materials, 148, 476-483.

https://doi.org/10.1016/j.conbuildmat.2017.05.050

[19] Taylor, P., \& Airey, G. D. (2007). State of the Art Report on Ageing Test Methods for Bituminous Pavement Materials State of the Art Report on Ageing Test Methods for Bituminous Pavement Materials, (December 2012), 37-41. https://doi.org/10.10850/1029843042000198568

[20] Zheng, D., Qian, Z. dong, Liu, Y., \& Liu, C. bo. (2018). Prediction and sensitivity analysis of long-term skid resistance of epoxy asphalt mixture based on GA-BP neural network. Construction and Building Materials, 158, 614623. https://doi.org/10.1016/j.conbuildmat.2017.10.056 